\title{
Sulforaphane protects rabbit corneas against oxidative stress injury in keratoconus through activation of the Nrf-2/HO-1 antioxidant pathway
}

\author{
RUIXING LIU and XIAOMING YAN \\ Department of Ophthalmology, The First Hospital of Peking University, Beijing 100034, P.R. China
}

Received March 15, 2018; Accepted July 30, 2018

DOI: $10.3892 / \mathrm{ijmm} .2018 .3820$

\begin{abstract}
The aim of the present study was to examine whether activation of the nuclear factor E2-related factor 2 (Nrf-2)/heme oxygenase-1 (HO-1) antioxidant pathway in the cornea was involved in the protective effect of sulforaphane (SF) following keratoconus (KC) injury. Following epithelial debridement, collagenase type II was applied in $\mathrm{KC}$ groups at room temperature for $30 \mathrm{~min}$. Following this, rabbits were administered with a subconjunctival (s.c.) injection of SF or placebo (maize oil) daily for a total of 2 weeks. To investigate whether HO-1 was involved in the Nrf-2-related antioxidant pathway, rabbits were injected with zinc (II) protoporphyrin IX (ZnPP IX, s.c.) treatment in combination with SF $24 \mathrm{~h}$ following the application of collagenase type II. The protective effects of SF were evaluated by examining the mean keratometry $(\mathrm{Km})$ and central cornea thickness (CCT), measuring reactive oxygen species (ROS) production using immunofluorescent staining, and analyzing the protein expression of NADPH oxidase (Nox) family members Nox-2 and Nox-4, and Nrf-2 and HO-1 using immunohistochemistry and western blot analysis. The mRNA levels of Nox-2, Nox-4, Nrf-2 and HO-1 were quantitatively detected by reverse transcription-quantitative polymerase chain reaction (RT-qPCR) analysis. No significant difference in $\mathrm{Km}$ or CCT was observed among groups prior to surgery ( $\mathrm{P}=0.700$ and $\mathrm{P}=0.982$, respectively). $\mathrm{KC}$ induced an apparent increase of ROS generation, and caused a significant increase in $\mathrm{Km}$ and a significant decrease in CCT. These changes were neutralized or reversed by SF treatment. Simultaneously, SF treatment decreased the expression of Nox-2 and Nox-4, and enhanced the expression of Nrf-2 and $\mathrm{HO}-1$ in the $\mathrm{KC}$ corneas. The RT-qPCR results indicated that $\mathrm{SF}$ induced downregulation of the mRNA expression of
\end{abstract}

Correspondence to: Professor Xiaoming Yan, Department of Ophthalmology, The First Hospital of Peking University, 8 Xishiku Street, Xicheng, Beijing 100034, P.R. China

E-mail: yanxiaoming7908@163.com

Key words: sulforaphane, keratoconus rabbits, oxidative stress, nuclear factor E2-related factor 2, heme oxygenase-1
Nox-2 and Nox-4, and upregulation of the mRNA expression of Nrf-2 and HO-1 following KC injury. The HO-1 inhibitor, $\mathrm{ZnPP}$ IX, counteracted the protective effects of SF on KC corneas. Therefore, the present study provided evidence that activation of the Nrf-2/HO-1 signal transduction pathway may partially promote the protective effect of the antioxidant $\mathrm{SF}$ in the KC cornea.

\section{Introduction}

Keratoconus (KC) is the leading cause of eye blindness. Typically, $\mathrm{KC}$ begins in adolescence and progresses until the patient is aged 30-40 years, when it usually arrests (1). KC is characterized by the conical protrusion of the cornea and is accompanied by corneal stromal thinning (2). Patients with $\mathrm{KC}$ have anomalous corneal astigmatism and myopia, which can result in progressive visual impairment and may necessitate corneal transplantation in order to maintain or improve vision (1). Corneal transplantation is expensive and donated corneas are scarce. To date, there have been no investigations of drugs for KC. Therefore, there is a pressing need to identify effective drugs to maintain normal function of the cornea and to stop or slow down the development of $\mathrm{KC}$.

There is currently no therapeutic target associated with the disease mechanism of $\mathrm{KC}$, as the pathology remains to be fully elucidated. Certain factors are associated with the pathogenesis of $\mathrm{KC}$, including environmental and genetic factors $(3,4)$, oxidative stress and cytokine signaling. Numerous studies have demonstrated the effect of oxidative stress on the pathogenesis of $\mathrm{KC}$ disease, and oxidative damage occurs in this corneal disorder (5-8). Oxidative stress is a sign of reactive oxygen species (ROS) accumulation, and cultured KC fibroblasts exhibit increased ROS generation compared with normal cultures $(7,8)$. Therefore, there has been considerable interest in the potential of developing antioxidative therapies for KC-associated damage.

Nuclear factor E2-related factor 2 (Nrf-2) is key role in antioxidant/electrophile response element (ARE/EpRE)-regulated gene expression (9), via binding to ARE/EpRE and transactivating downstream target genes. ARE/EpRE-regulated phase II detoxifying antioxidants and enzymes, including heme oxygenase-1 (HO-1), are important antioxidants involved in regulating elevated oxidative stress and maintaining the redox status in numerous biological settings $(10,11)$. Nrf-2 
is sequestered in the cytosol by Kelch-like ECH-associated protein 1 (Keap1) and is targeted for proteasomal degradation under physiological conditions $(9,12)$. Under oxidative stress conditions, Nrf-2 is dissociated from Keap1, constitutively accumulates in the nucleus and stimulates the transcription of cytoprotective genes encoding antioxidant enzymes, including the stress response protein HO-1 $(9,12)$.

The Nrf-2 activator sulforaphane (SF), as a potent inducer of phase II enzymes, is a natural compound derived from cruciferous vegetables, particularly broccoli (13). It has been demonstrated that SF may have a neuroprotective function in several experimental animal models (14-16). Numerous pathological features can be manifestations of ROS-associated functional defects. Antioxidant exposure has a favorable effect on the Nrf-2/ARE signaling pathway in several types of tissues and cells. It is well established that SF has protective effects that lead to an increase in the expression of numerous antioxidant proteins (17). SF promotes the translation of cytoprotective proteins by activating the Keap1/Nrf-2/ARE pathway and has a catalytic effect. It has also been reported that other antioxidative compounds increase antioxidant gene expression and downregulate ROS-generating oxidase gene expression in KC stromal cells (18). The present study aimed to investigate whether the treatment of KC keratocytes with the antioxidant SF advantageously alters the protein expression of molecules involved in ROS-associated pathways (endogenous antioxidant proteins and ROS-synthesizing oxidases). As the Nrf-2/ARE axis is being considered for therapeutic drug identification (19), the data presented in the present highlight the importance of monitoring the pharmacological actions of Nrf-2 activators (SF) in conditions that simulate the pathological states associated with KC.

\section{Materials and methods}

Animals. A total of 56 female New Zealand white rabbits, 6-7 months old, weighing 3.0-3.5 $\mathrm{kg}$, were used in the present study. The animals were obtained from Beijing FYY Laboratory Animal Co., Ltd. (Beijing, China; SCXK 2014-0012). The rabbits were housed in a controlled environment with a 12 -h light/dark cycle. Food and water were available ad libitum. Continuous clinical care $(24 \mathrm{~h}$ per day/7 days per week) was provided throughout the investigation to ensure timely intervention when required. The experimental protocol was approved by the Ethical Committee of Peking University First Hospital (Beijing, China). All animals used in the present study were treated in accordance with the Association for Research in Vision and Ophthalmology Statement for the Use of Animals in Ophthalmic and Vision Research (https://www. arvo.org/About/policies/statement-for-the-use-of-animals-in-o phthalmic-and-vision-research/).

Animal model of KC. Briefly, collagenase type II (Worthington Biochemical Corporation, Lakewood, NJ, USA) was obtained in powder form and dissolved in balanced salt solution with 15\% dextran (Adamas Reagent Co., Ltd., Shanghai, China) to a final concentration of $5 \mathrm{mg} / \mathrm{ml}$. The rabbits were anesthetized intravenously with $0.6 \mathrm{ml} / \mathrm{kg}$ of $5 \%$ sodium pentobarbital $(30 \mathrm{mg} / \mathrm{kg})$. Topical anesthesia using $0.4 \%$ oxybuprocaine hydrochloride eye drops was applied to the eyes. Following epithelial debridement, corneal trephines were placed on the cornea. In the right eye, $200 \mu \mathrm{l}$ of $5 \mathrm{mg} / \mathrm{ml}$ collagenase type II solution was transferred into the corneal trephines, and the cornea was immersed in collagenase type II solution at room temperature $\left(24^{\circ} \mathrm{C}\right)$ for $30 \mathrm{~min}(20)$. The solution was then removed with cotton swabs, and the cornea was rinsed with $0.9 \%$ sodium chloride solution. The right eyes were treated as the experimental eyes throughout the experiment. The left eyes did not undergo any treatment. Prior to surgery, the rabbit eyes underwent slit-lamp examinations, which were repeated every day during the 14-day study.

Experimental design. At $24 \mathrm{~h}$ following induction of the $\mathrm{KC}$ model, SF (D,L-sulforaphane, $5 \mathrm{mg} / \mathrm{ml}$, Sigma-Aldrich; Merck KGaA, Darmstadt Germany; dissolved in maize oil) (21) or maize oil (placebo) was administered via a subconjunctival (s.c.) injection daily for a total of 2 weeks until the animals were sacrificed. As an HO-1 inhibitor, zinc (II) protoporphyrin IX (ZnPP IX, 5 mg/ml; Sigma-Aldrich; Merck KGaA), was administered $24 \mathrm{~h}$ following application of collagenase type II solution via s.c. injection in combination with SF. The ZnPP IX was dissolved in $0.1 \mathrm{~mol} / 1 \mathrm{NaOH}(1 \mathrm{ml})$. The $\mathrm{pH}$ of the solution was adjusted to $7.4 \mathrm{using} 1 \mathrm{~mol} / \mathrm{l} \mathrm{HCl}$, and then diluted to the final concentration required using $0.9 \%$ $\mathrm{NaCl}(22,23)$. All drug treatments were administered at a fixed time each day. A total of 56 rabbits were divided randomly into four experimental groups ( $\mathrm{n}=14$ per group): Sham-operated group (eyes subjected to the same protocol as model rabbits, but the applied solution lacked collagenase type II; Control); placebo group (rabbits were injected s.c. with maize oil $24 \mathrm{~h}$ following corneal KC model establishment; KC); SF-treated group (rabbits were injected s.c. with SF $24 \mathrm{~h}$ following corneal $\mathrm{KC}$ model establishment; $\mathrm{KC}+\mathrm{SF}$ ); the ZnPP-treated group (SF and ZnPP IX were injected s.c. $24 \mathrm{~h}$ following corneal $\mathrm{KC}$ model establishment; $\mathrm{KC}+\mathrm{SF}+\mathrm{ZnPP})$. The rabbits were sacrificed by administering an overdose of pentobarbital sodium 14 days following establishment of the corneal KC model.

Corneal keratometry $(\mathrm{Km})$. Km was performed on the day prior to surgery and 14 days following surgery using a handheld keratometer (Suowei; Tianjin Suowei, Tianjin, China). Eight measurements were recorded at each time point, and the mean $\mathrm{Km}$ was recorded in diopters (D) in all experimental groups.

Corneal pachymetry. Central cornea thickness (CCT) was recorded on the day prior to surgery and 14 days following surgery using a handheld pachymeter (PachPen; Acctome Ultrasound, Malvern, PA, USA) under topical anesthesia. Six measurements were recorded at each time point and the mean CCT $(\mu \mathrm{m})$ was recorded in all experimental groups.

Detection of ROS production. ROS production was evaluated based on dihydroethidium (DHE; Invitrogen; Thermo Fisher Scientific, Inc., Waltham, MA, USA) measurements, as previously described (24). Following removal of the eyeball, the fresh cornea was harvested and immediately flash-frozen in liquid nitrogen ( $\mathrm{n}=4$ per group). The frozen sections $(10-\mu \mathrm{m}$ thick) were washed three times with 0.01 M PBS (pH 7.2-7.4) 
and then incubated with $5 \mathrm{mM}$ DHE dissolved in PBS solution for $30 \mathrm{~min}$ at room temperature. DHE specifically reacted with superoxide anion free radicals and was transformed into red fluorescent compounds. The sections were observed and images were captured with a fluorescence microscope (Eclipse Ci-E; Nikon Corporation, Tokyo, Japan) under the same exposure conditions, and the average optical density of the fluorescent dye in the corneal stroma layer was measured using randomly selected images. Three fields of view were observed per animal. The fluorescence intensities of the DHE-tagged cells were quantified with Adobe Photoshop CS5 (Adobe Systems, Inc., Beijing, China).

Immunohistochemical staining. The rabbits were sacrificed by intravenous injection with an overdose of pentobarbital sodium on day 14 ( $n=4$ per group). The eyeballs were then removed and post-fixed with $4 \%$ paraformaldehyde overnight, processed into paraffin wax, cut into $5-\mu \mathrm{m}$ thick sections and placed on glass slides. The sections were dehydrated at $37^{\circ} \mathrm{C}$ overnight, dewaxed and then rehydrated. Hematoxylin and eosin (H\&E) staining was performed to detect changes in corneal tissue structure in the four experimental groups. Hydrogen peroxide (3\%) was used to block endogenous peroxidase for $20 \mathrm{~min}$, and the sections were then heated to promote antigen repair in $\mathrm{pH} 6.0$ citrate buffer. The sections were then placed into cold water prior to immunostaining. Following $30 \mathrm{~min}$ of incubation with normal serum (I5506-100MG; Sigma-Aldrich; Merck $\mathrm{KGaA}$ ), the sections were incubated with primary antibodies at $4^{\circ} \mathrm{C}$ for $24 \mathrm{~h}$. The primary antibodies were as follows: Rabbit polyclonal anti-NADPH oxidase (Nox)-2 (1:200; cat. no. ab80508; Abcam, Cambridge, MA, USA), rabbit polyclonal anti-Nox-4 (1:200; cat. no. NB110-58849; Novus Biologicals, LLC, Littleton, CO, USA), rabbit polyclonal anti-Nrf-2 (1:500; cat. no. bs-1074R; Bioss, Beijing, China) or rabbit polyclonal anti-HO-1 (1:100; cat. no. ADI-SPA-895-F, Enzo Life Sciences, Inc., Farmingdale, NY, USA). The immunoreaction was localized using a 2-step Plus Poly-HRP Anti-Mouse/Rabbit IgG Detection system (PV-9000, OriGene Technologies, Inc., Beijing, China). HRP activity was shown via dipping the sections in a compound containing 3,3'-diaminobenzidine (DAB) chromogen and DAB substrate (ZLI-9018, OriGene Technologies, Inc.) at room temperature for $5 \mathrm{~min}$. The sections were mounted, air-dried, dehydrated and cover-slipped. No positive signals were detected in any negative control samples. Images of the stained sections were captured using an Olympus optical microscope (Olympus Corporation, Tokyo, Japan).

Western blot analysis. The rabbits were sacrificed by intravenous injection of an overdose of sodium pentobarbital on day 14 ( $n=3$ per group). Briefly, the cornea was separated and frozen at $-80^{\circ} \mathrm{C}$ within $2 \mathrm{~min}$ of enucleation. The cornea was then sonicated on ice with lysis buffer (Santa Cruz Biotechnology, Inc., Dallas, TX, USA). The protein concentration of the extracts was detected $(n=3$ per group) using a bicinchoninic acid protein quantification kit (cat. no. P1511, Applygen Technologies, Inc., Beijing, China). Equal quantities of protein $(20 \mu \mathrm{g} / \mathrm{channel})$ were resolved by $10 \%$ or $12 \%$ SDS-PAGE. The proteins were then electrophoretically transferred onto Immun-Blot PVDF membranes (cat. no. 162-0177, Bio-Rad Laboratories, Inc., Hercules, CA, USA), which were blocked with $5 \%$ non-fat milk and then incubated with the following antibodies overnight at $4{ }^{\circ} \mathrm{C}$ : Rabbit polyclonal anti-Nox-2 (1:1,000; cat. no. ab80508), rabbit polyclonal anti-Nox-4 (1:500; cat. no. NB110-58849); rabbit polyclonal anti-Nrf-2 (1:500; cat. no. bs-1074R), rabbit polyclonal anti-HO-1 (1:500; cat. no. ADI-SPA-895-F) and mouse monoclonal antibody against $\beta$-actin $(1: 2,000$; cat. no. A1978, Sigma-Aldrich; Merck KGaA). Then, the membranes were washed and incubated with a Peroxidase-AffiniPure Goat Anti-Mouse IgG (H+L) (1:2,000; cat. no. 115-035-003; Jackson ImmunoResearch Laboratories, Inc., West Grove, PA, USA) and a peroxidase-conjugated donkey anti-rabbit $\operatorname{IgG}(\mathrm{H}+\mathrm{L})$ (1:2,000; cat. no. 711-035-152; Jackson ImmunoResearch Laboratories, Inc.) for $1 \mathrm{~h}$ at room temperature. The protein bands were visualized and analyzed using Super ECL hypersensitive luminescent solution (cat. no. P1020; Applygen Technologies, Inc.) and a gel image analysis system (GBOX-CHEMI-XT4; Synoptics Ltd., Cambridge, UK) according to the manufacturer's protocol. The immunoblot experiments were repeated at least three times independently for quantification ( $n=3$ per group) and ImageJ software (version 1.4.3; National Institutes of Health, Bethesda, MD, USA) was used for analysis.

RNA extraction and reverse transcription-quantitative polymerase chain reaction $(R T-q P C R)$ analysis. The mRNA expression of all samples was evaluated by RT-qPCR analysis as previously described $(25,26)$. Briefly, total RNA was extracted using the RNA Mini extraction kit (cat. no. 12183555; Thermo Fisher Scientific, Inc.). The purity and concentration of RNA were quantified using a Nanodrop Spectrophotometer ND-1000 ( $n=3$ per group). cDNA synthesis was performed using a PrimeScript RT reagent kit (cat. no. RR047A; Takara Biotechnology Co., Ltd., Dalian, China), according to the manufacturer's protocol, with an ARKTIK Thermal Cycler (Thermo Fisher Scientific, Inc.). qPCR was performed using SYBR Premix Ex Taq II (cat. no. RR820A; Takara Biotechnology Co., Ltd.). PCR was performed with $10 \mathrm{ng}$ cDNA in a $20-\mu \mathrm{l}$ reaction system $(2 \mu \mathrm{l}$ cDNA, $0.8 \mu \mathrm{l} 10 \mu \mathrm{M}$ forward primer, $0.8 \mu \mathrm{l} 10 \mu \mathrm{M}$ reverse primer, $10 \mu 1$ PCR mix buffer, and $6.4 \mu 1$ sterilized distilled water) using a PikoReal 96 Real-Time PCR system (Thermo Fisher Scientific, Inc.) according to the manufacturer's protocol. The PCR conditions were as follows: $2 \mathrm{~min}$ of $50^{\circ} \mathrm{C}$, $30 \mathrm{sec}$ at $94^{\circ} \mathrm{C}$ and 40 cycles of $5 \mathrm{sec}$ at $94^{\circ} \mathrm{C}$ and $34 \mathrm{sec}$ at $60^{\circ} \mathrm{C}$. The primers used are listed in Table I (AuGCT DNA-SYN Biotechnology Co., Ltd., Beijing, China). The relative mRNA expression was normalized against the expression of $\beta$-actin and calculated using the $2^{-\Delta \Delta \mathrm{Cq}}$ method (26). By analyzing the melting curve, the property and purity of the amplified products were determined. All experiments were repeated at least three times.

Statistical analysis. All values are expressed as the mean \pm standard deviation. Data analysis was performed using GraphPad Prism 5 (GraphPad Software, Inc., La Jolla, CA, USA). The results of multiple groups were compared using one-way analysis of variance followed by Tukey's post hoc test with SPSS 17.0 (SPSS, Inc., Chicago, IL, USA). 
Table I. Gene markers and corresponding primers.

\begin{tabular}{lll}
\hline Gene & \multicolumn{1}{c}{ Forward sequence $\left(5^{\prime}-3^{\prime}\right)$} & \multicolumn{1}{c}{ Reverse sequence $\left(5^{\prime}-3^{\prime}\right)$} \\
\hline Nox-2 & TGTGAATGCCCGAGTCAACA & AACCGCGTTACAGCCACTAA \\
Nox-4 & CTAGAGGGCGGTGCTTTACC & GCCACCAGTGCTGGACATAG \\
Nrf-2 & ACACAGGTGAATTCGGAAGACAGAG & GCATAGCAGAGAGCTGGATCAGAAG \\
HO-1 & TGAACTCCCTGGAGATGACC & GGTGGAGTCTTGGGTCCTG \\
& CATCCACGAGACCACCTTCAACT & GATGATCTTGATCTTCATGGTGCTG
\end{tabular}

Nox, NADPH oxidase; HO-1, heme oxygenase 1.

Table II. Comparison of the Km and CCT in the four experimental groups ( $\mathrm{n}=14$ per group).

\begin{tabular}{|c|c|c|c|c|}
\hline Factor & Group & Day 0 & Day 14 & Day 14-Day 0 \\
\hline \multirow[t]{5}{*}{$\mathrm{Km}$ (D) } & Control & $47.56 \pm 1.71$ & $46.62 \pm 2.22$ & $-0.94 \pm 0.70$ \\
\hline & $\mathrm{KC}$ & $47.55 \pm 1.60$ & $49.06 \pm 1.59$ & $1.51 \pm 0.50$ \\
\hline & $\mathrm{KC}+\mathrm{SF}$ & $46.90 \pm 1.68$ & $47.54 \pm 1.41$ & $-0.64 \pm 0.40$ \\
\hline & $\mathrm{KC}+\mathrm{SF}+\mathrm{Znpp}$ & $47.43 \pm 1.78$ & $48.19 \pm 1.74$ & $0.77 \pm 0.35$ \\
\hline & P-value & 0.700 & 0.005 & $<0.001$ \\
\hline \multirow[t]{5}{*}{$\mathrm{CCT}(\mu \mathrm{m})$} & Control & $356.36 \pm 21.31$ & $358.14 \pm 18.93$ & $1.77 \pm 4.17$ \\
\hline & $\mathrm{KC}$ & $353.93 \pm 24.11$ & $331.79 \pm 18.10$ & $-22.14 \pm 8.00$ \\
\hline & $\mathrm{KC}+\mathrm{SF}$ & $356.57 \pm 18.17$ & $351.71 \pm 16.12$ & $-4.86 \pm 6.34$ \\
\hline & $\mathrm{KC}+\mathrm{SF}+\mathrm{Znpp}$ & $354.86 \pm 13.55$ & $335.14 \pm 18.64$ & $-19.71 \pm 9.81$ \\
\hline & P-value & 0.982 & $<0.001$ & $<0.001$ \\
\hline
\end{tabular}

Data are presented as the mean \pm standard deviation. P-values were determined by one-way analysis of variance among the four groups. Control, sham-operated group (eyes subjected to the same protocol but the applied solution lacked collagenase type II); KC, vehicle group (animals injected subconjunctivally with maize oil $24 \mathrm{~h}$ following corneal KC model establishment); KC + SF, SF-treated group (animals injected subconjunctivally with SF $24 \mathrm{~h}$ following corneal $\mathrm{KC}$ model establishment); $\mathrm{KC}+\mathrm{SF}+\mathrm{ZnPP}$, the SF and ZnPP IX-treated group (SF and ZnPP IX injected subconjunctivally $24 \mathrm{~h}$ following corneal $\mathrm{KC}$ model establishment.). D, diopters. CCT, central cornea thickness; KC, keratoconus; SF, sulforaphane; ZnPP IX, zinc (II) protoporphyrin IX.

$\mathrm{P}<0.05$ was considered to indicate a statistically significant difference.

\section{Results}

Changes in corneal tissue structure among the four experimental groups. No obvious inflammatory reaction was observed in any of the rabbits following the procedure in the four experimental groups (Control, $\mathrm{KC}, \mathrm{KC}+\mathrm{SF}$, and $\mathrm{KC}+\mathrm{SF}$ $+\mathrm{ZnPP}$ groups). The results of the H\&E staining indicated that the corneal tissue structures of the four experimental groups were intact at day 14 post-surgery, and the cell morphology was normal (Fig. 1). The corneal endothelial cells were lost in certain tissues due to section preparation and other reasons. The corneal epithelium in the four groups consisted of 5-6 layers of stratified squamous epithelium, and was closely connected with the stroma, suggesting that the epithelium had returned to normal (Fig. 1A-D). Compared with the Control group, the corneal stromal fibers were loosely arranged and the gap between the collagen fibers was increased in the $\mathrm{KC}$ group. Compared with the Control group, there was no marked change in the corneal tissue structures of the $\mathrm{KC}+\mathrm{SF}$ and $\mathrm{KC}$
$+\mathrm{SF}+\mathrm{ZnPP}$ groups (Fig. 1E-L). SF treatment did not visibly change the corneal structure.

Changes in Km and CCT among the four experimental groups. Prior to surgery, there was no marked difference in $\mathrm{Km}$ among the four experimental groups ( $\mathrm{n}=14$ per group; Table II; 47.56 $\pm 1.71,47.55 \pm 1.60,46.90 \pm 1.68$ and $47.43 \pm 1.78 \mathrm{D}$, respectively, $\mathrm{P}=0.700)$ or $\mathrm{CCT}(356.36 \pm 21.31,353.93 \pm 24.11$, $356.57 \pm 18.17$ and $354.86 \pm 13.55 \mu \mathrm{m}$, respectively, $\mathrm{P}=0.982$ ). Following surgery, the changes in $\mathrm{Km}$ values in the four experimental groups were $-0.94 \pm 0.70,1.51 \pm 0.50,-0.64 \pm 0.40$ and $0.77 \pm 0.35 \mathrm{D}$, respectively (Table II). The changes in CCT in the four experimental groups were $1.77 \pm 4.17,-22.14 \pm 8.00$, $-4.86 \pm 6.34$ and $-19.71 \pm 9.81 \mu \mathrm{m}$, respectively (Table II). All values represent a change from the pre-surgery baselines (day 14-day 0). Graphic quantification of the changes in $\mathrm{Km}$ and CCT in all experimental groups is presented in Fig. 2. $\mathrm{Km}$ in the $\mathrm{KC}$ group was significantly increased compared with that in the Control group (Fig. 2A; $\mathrm{P}<0.001$ ). $\mathrm{Km}$ in the $\mathrm{KC}+$ $\mathrm{SF}$ group was significantly reduced compared with that in the $\mathrm{KC}$ group (Fig. 2A; $\mathrm{P}<0.001$ ). The change in $\mathrm{Km}$ in the $\mathrm{KC}$ $+\mathrm{SF}+\mathrm{ZnPP}$ group was more marked compared with that in 

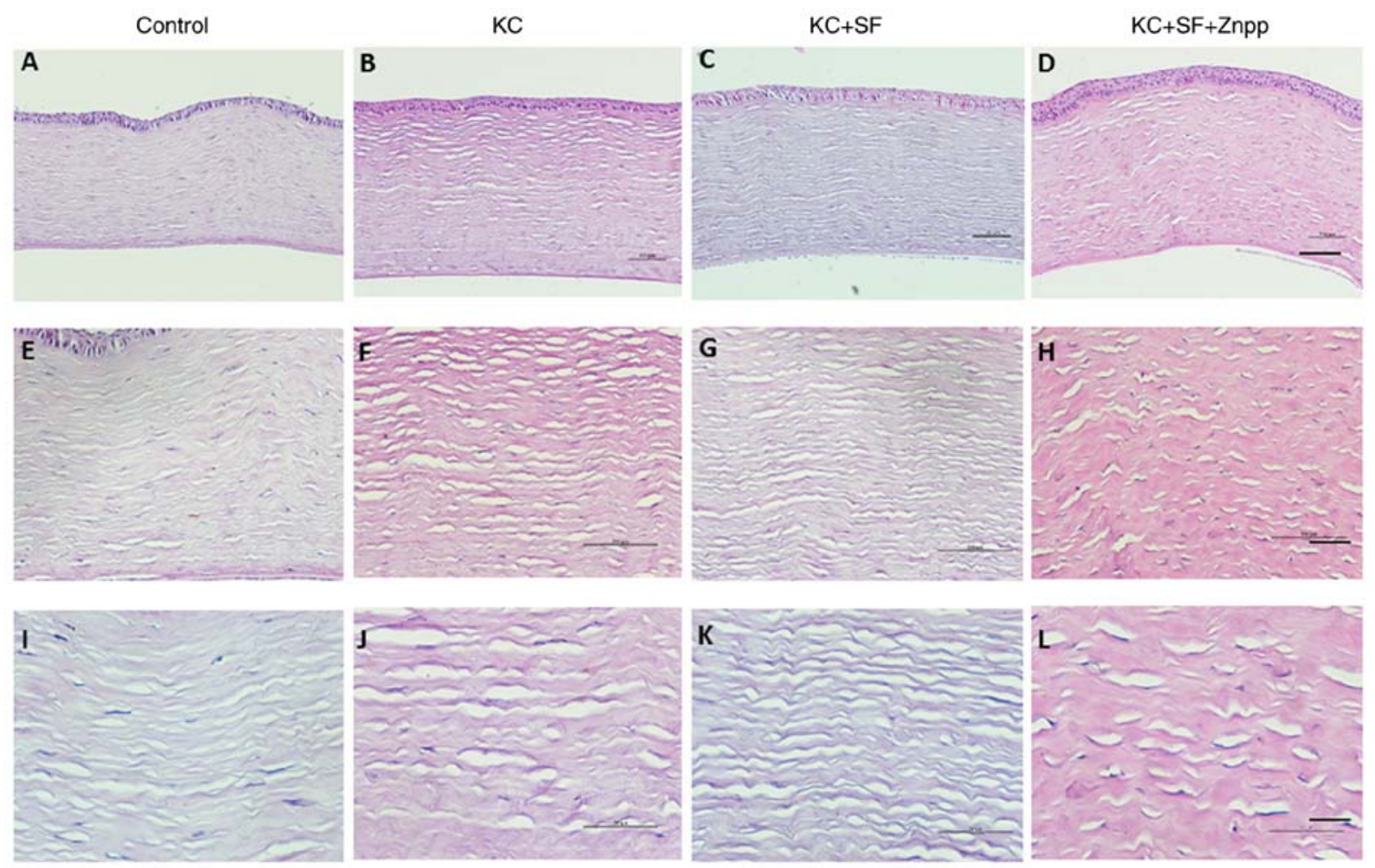

Figure 1. Changes in corneal tissue structure among the four experimental groups. H\&E staining was performed to detect changes in corneal tissue structure among the four experimental groups. Representative micrographs of corneal sections stained with H\&E from (A) Control, (B) KC, (C) KC + SF, and (D) KC $+\mathrm{SF}+\mathrm{Znpp}$ groups with a 10X objective lens (x100 magnification; scale bar=100 $\mu \mathrm{m}$ ); (E) Control, (F) KC, (G) KC $+\mathrm{SF}$, and $(\mathrm{H}) \mathrm{KC}+\mathrm{SF}+\mathrm{Znpp}$ groups with a 20X objective lens (x200 magnification; scale bar=50 $\mu \mathrm{m}$ ); and (I) Control, (J) KC, (K) KC + SF, and (L) KC + SF + Znpp groups with a 40X objective lens (x400 magnification, scale bar=25 $\mu \mathrm{m}$ ). Control, sham-operated group (eyes subjected to the same protocol but the applied solution lacked collagenase type II); KC, vehicle group (injected s.c. with maize oil $24 \mathrm{~h}$ following corneal KC model establishment); KC + SF, SF-treated group (animals were injected s.c. with SF $24 \mathrm{~h}$ following corneal KC model establishment); KC + SF + ZnPP, SF and ZnPP-treated group (SF and ZnPP IX injected s.c. $24 \mathrm{~h}$ following corneal KC model establishment). H\&E, hematoxylin and eosin; s.c., subconjunctivally; KC, keratoconus; SF, sulforaphane; ZnPP IX, zinc (II) protoporphyrin IX.

A
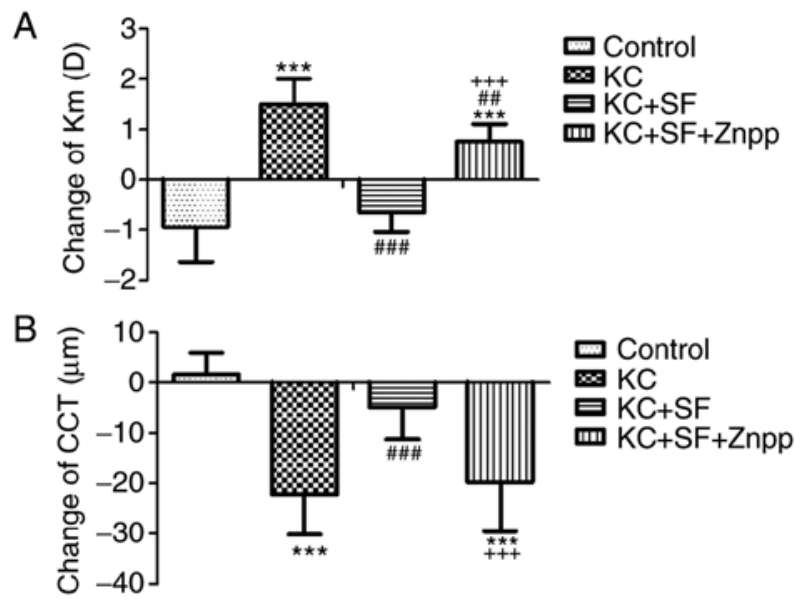

Figure 2. Changes in $\mathrm{Km}$ and $\mathrm{CCT}$ among the four experimental groups. (A) Graphic quantification of the changes in $\mathrm{Km}$ in the four experimental groups. (B) Graphic quantification of changes in CCT in the four experimental groups. All values represent a change from pre-surgery baselines (day 14-day 0). Data are presented as the mean \pm standard deviation; $n=14$ per group. ${ }^{* * *} \mathrm{P}<0.001$, vs. Control; ${ }^{\# \#} \mathrm{P}<0.01$ and ${ }^{\# \# \#} \mathrm{P}<0.001$, vs. KC group ${ }^{++} \mathrm{P}<0.001$, vs. $\mathrm{KC}+\mathrm{SF}$ group. KC, keratoconus; SF, sulforaphane; ZnPP IX, zinc (II) protoporphyrin IX; Km, keratometry; CCT, central cornea thickness.

the $\mathrm{KC}+\mathrm{SF}$ group (Fig. 2A; $\mathrm{P}<0.001$ ). $\mathrm{CCT}$ in the $\mathrm{KC}$ group was significantly reduced compared with that in the Control group (Fig. 2B; $\mathrm{P}<0.001$ ). $\mathrm{CCT}$ in the $\mathrm{KC}+\mathrm{SF}$ group was significantly enhanced compared with that in the $\mathrm{KC}$ group (Fig. 2B; $\mathrm{P}<0.001$ ). The change in $\mathrm{CCT}$ in the $\mathrm{KC}+\mathrm{SF}+\mathrm{ZnPP}$ group was significantly $=$ decreased compared with that in the $\mathrm{KC}+\mathrm{SF}$ group (Fig. 2B; $\mathrm{P}<0.001$ ). The KC model exhibited a significant increase in $\mathrm{Km}$ and a significant decrease in CCT, and these effects were weakened or reversed by SF. ZnPP IX, the HO-1 inhibitor, neutralized the protective effect of SF on the KC cornea.

SF downregulates ROS generation in KC corneas. The production of ROS in fresh corneas was measured with DHE staining in all groups. As shown in Fig. 3, the basal level of ROS was low in the Control group corneas (Fig. 3A). However, ROS generation was increased markedly in the $\mathrm{KC}$ corneas (Fig. 3B), and this effect was decreased with SF treatment (Fig. 3C). The production of ROS was enhanced in the $\mathrm{KC}+\mathrm{SF}+\mathrm{ZnPP}$ group (Fig. 3D). Representative images of corneal sections stained with DAPI were obtained from each group (Fig. 3E-H). The merged images with double-label immunofluorescent staining using antibodies against DHE and DAPI are shown in Fig. 3I-L. ROS level analysis in the stroma of the cornea was consistent with the immunofluorescent results (Fig. 3M, n=4 per group).

SF downregulates the expression levels of Nox-2 and Nox-4 in KC corneas. The Nox family of proteins is considered to 

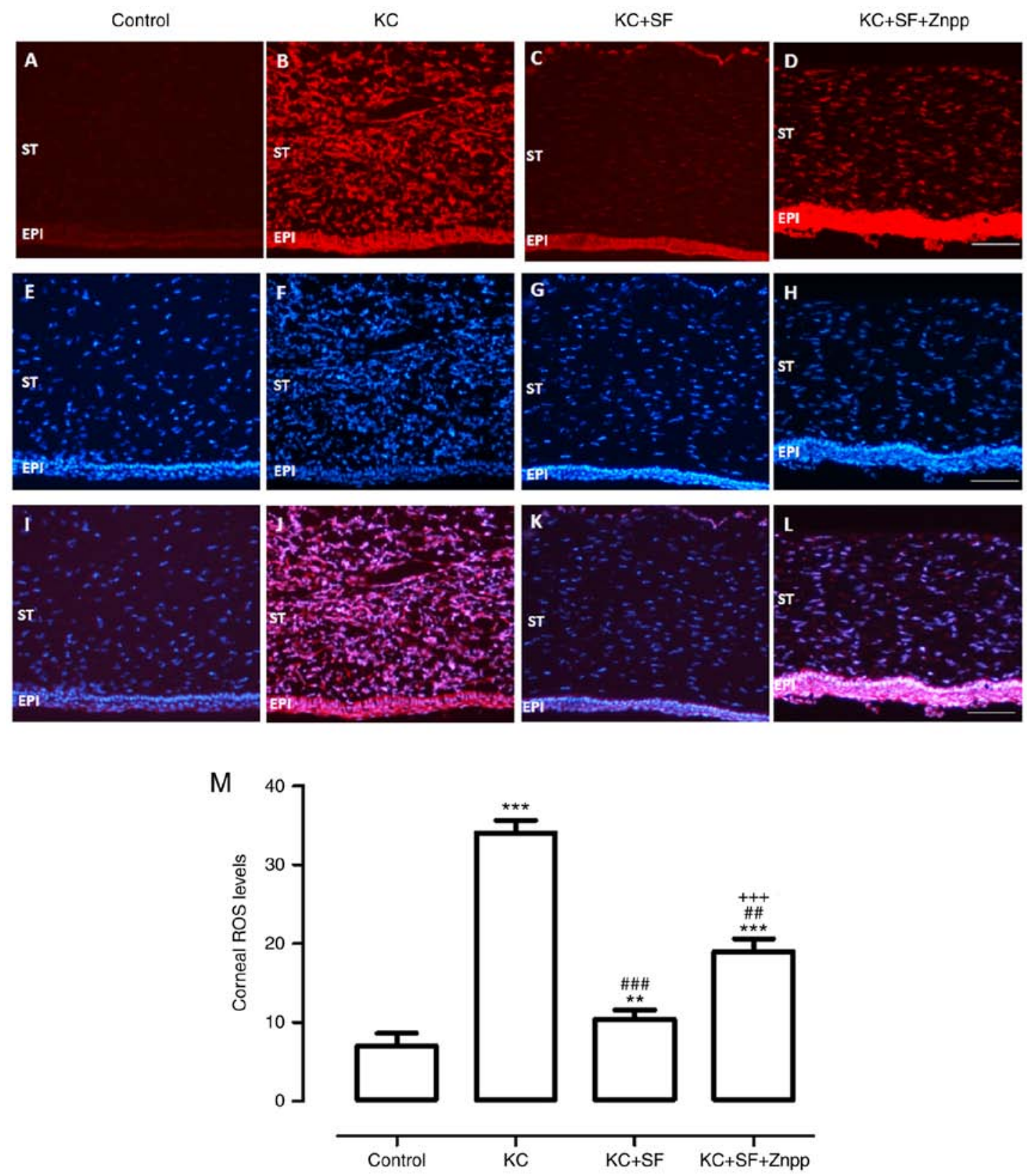

Figure 3. SF downregulates ROS generation in KC corneas. ROS generation in fresh corneas was examined by DHE staining. Representative micrographs of corneal sections stained with DHE (red) in the (A) Control, (B) KC, (C) KC + SF, and (D) KC + SF + Znpp groups. Representative micrographs of corneal sections stained with DAPI (blue) in the (E) Control, (F) KC, (G) KC + SF, and (H) KC + SF + Znpp groups. Merged images of staining in the (I) Control, (J) KC, (K) KC + SF, and (L) KC + SF + Znpp groups. Magnification, x200 scale bar=50 $\mu \mathrm{m}$. (M) Quantitative analysis of ROS levels in the entire cornea. The fluorescent intensities of DHE-labeled cornea were quantified using ImageJ. Data are presented as the mean $\pm \mathrm{SD} ; \mathrm{n}=4$ per group. ${ }^{* *} \mathrm{P}<0.01$ and ${ }^{* * * *} \mathrm{P}<0.001$, vs. Control; ${ }^{\# \# ~} \mathrm{P}<0.001$, vs. $\mathrm{KC}$ group; ${ }^{++} \mathrm{P}<0.001$, vs. $\mathrm{KC}+\mathrm{SF}$ group. $\mathrm{KC}$, keratoconus; SF, sulforaphane; ZnPP IX, zinc (II) protoporphyrin IX; DHE, dihydroethidium; ROS, reactive oxygen species; ST, corneal stroma; EPI, corneal epithelial layer.

be one of the most important ROS sources in the cornea, and Nox-2 and Nox-4 proteins are expressed at high levels in the corneal stromal cells of patients with KC $(8,27)$. Therefore, changes in the expression of Nox-2 and Nox-4 were evaluated in the corneas of the four experimental groups ( $\mathrm{n}=4$ per group). Images of the results are shown in Fig. 4A-L. The Control group had relatively low Nox-2 immunoreactivity throughout the cornea (Fig. 4A, E and I). In the KC group, there was more marked Nox-2 immunoreactivity throughout the entire cornea (Fig. 4B, F and J). The expression of Nox- 2 in the $\mathrm{KC}+\mathrm{SF}$ group was reduced compared with that in the $\mathrm{KC}$ group (Fig. 4C, G and $\mathrm{K}$ ). The expression of Nox- 2 in the $\mathrm{KC}+\mathrm{SF}+\mathrm{ZnPP}$ group was markedly enhanced compared with that in the $\mathrm{KC}+\mathrm{SF}$ group (Fig. 4D, H and L). Western blot analysis revealed that the basal level of Nox-2 in the Control group corneas was lower than that in the $\mathrm{KC}$ group corneas. $\mathrm{KC}$ induced a significant increase in the expression of Nox-2 in the cornea $(n=3$, Fig. $4 M ; P<0.001)$. The level of Nox-2 in the KC $+S F$ group was significantly decreased compared with that in the KC group (n=3, Fig. 4M; P<0.001). The level of Nox-2 in the $\mathrm{KC}+\mathrm{SF}+\mathrm{ZnPP}$ group was significantly increased compared with that in the $\mathrm{KC}+\mathrm{SF}$ group ( $=3$, Fig. $4 \mathrm{M} ; \mathrm{P}<0.05)$. As shown in Fig. 5, the Control group exhibited relatively low Nox-4 immunoreactivity throughout the cornea ( $n=4$, Fig. 5A, 

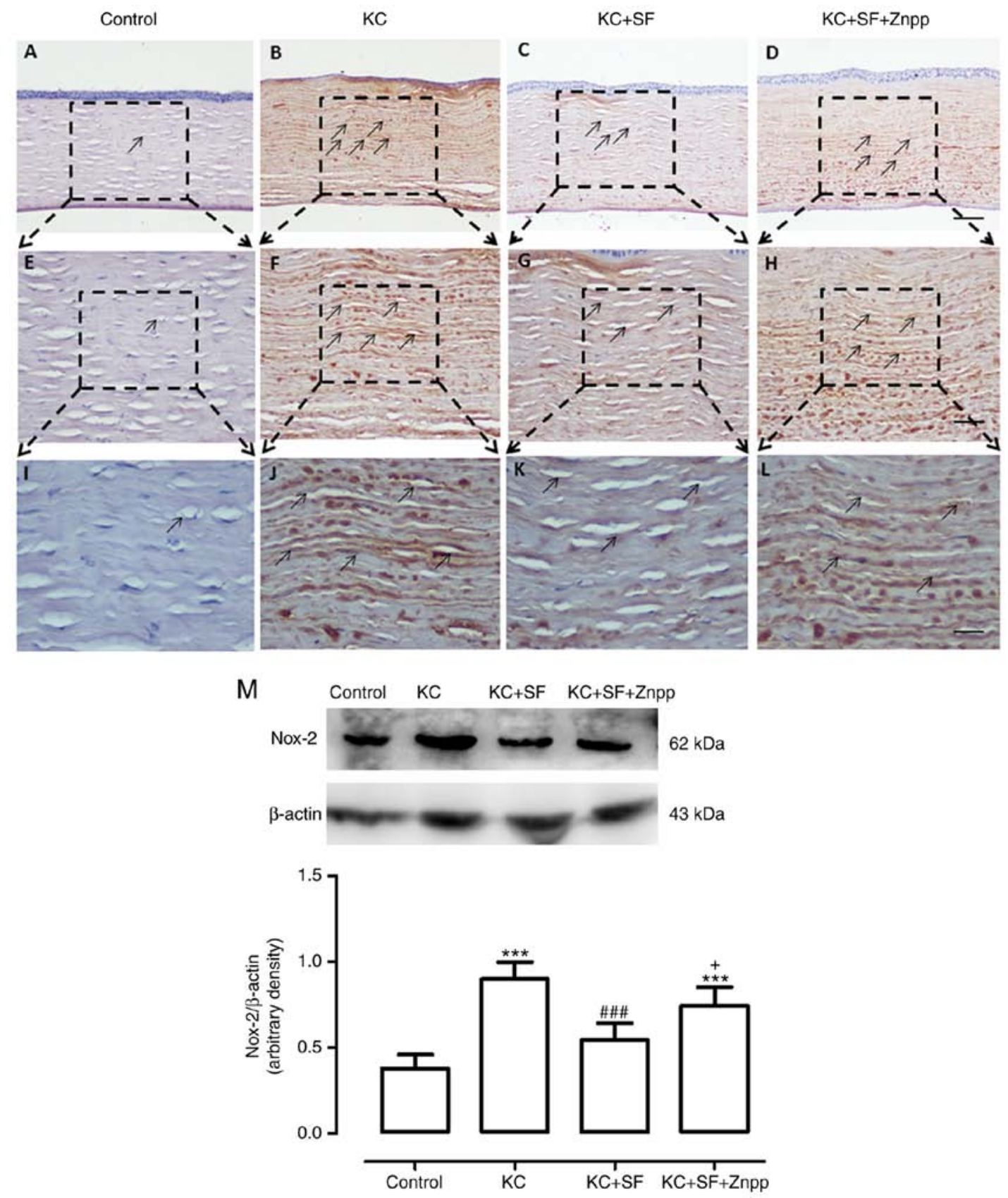

Figure 4. SF downregulates the expression level of Nox-2 in KC corneas. Representative micrographs of corneal sections obtained from each group stained with anti-Nox-2 antibody. Black arrows indicate Nox-2-positive cells. (A) Control, (B) KC, (C) KC + SF, and (D) KC + SF + Znpp groups with 10X objective lens (x100 magnification; scale bar=100 $\mu \mathrm{m}$. (E) Control, (F) KC, (G) KC + SF, and (H) HKC + SF + Znpp groups with 20X objective lens (x200 magnification; scale bar=50 $\mu \mathrm{m}$ ). (I) Control, (J) KC, $(\mathrm{K}) \mathrm{KC}+\mathrm{SF}$, and (L) $\mathrm{KC}+\mathrm{SF}+\mathrm{Znpp}$ groups with a 40X objective lens ( $\mathrm{x} 400$ magnification scale bar=25 $\mu \mathrm{m})$. (M) Representative immunoblotting indicating Nox-2 protein levels in the entire cornea (upper panel) and densitometric analysis of the expression of Nox-2 relative to the loading control (lower panel). Data are presented as the mean \pm standard deviation; $n=3$ per group. ${ }^{* * *} \mathrm{P}<0.001$, vs. Control; ${ }^{\# \# \#} \mathrm{P}<0.001$, vs. KC group; ${ }^{+} \mathrm{P}<0.05$, vs. $\mathrm{KC}+\mathrm{SF}$ group. KC, keratoconus; SF, sulforaphane; ZnPP IX, zinc (II) protoporphyrin IX; Nox, NAPDH oxidase.

$\mathrm{E}$ and I). In the $\mathrm{KC}$ group, there was more marked Nox-4 immunoreactivity throughout the entire cornea ( $n=4$, Fig. 5B, $\mathrm{F}$ and $\mathrm{J}$ ). The expression of Nox-4 in the $\mathrm{KC}+\mathrm{SF}$ group was more markedly decreased compared with that in the $\mathrm{KC}$ group ( $n=4$, Fig. 5C, G and K). The expression of Nox-4 in the $\mathrm{KC}+\mathrm{SF}+\mathrm{ZnPP}$ group was enhanced compared with that in the $\mathrm{KC}+\mathrm{SF}$ group ( $\mathrm{n}=4$, Fig. 5D, $\mathrm{H}$ and $\mathrm{L}$ ). Western blot analysis revealed that the basal level of Nox-4 in the control cornea was lower than that in the $\mathrm{KC}$ cornea. $\mathrm{KC}$ induced a significant increase in the expression of Nox-4 in the cornea $(n=3$, Fig. $5 \mathrm{M} ; \mathrm{P}<0.001)$. The level of Nox-4 in the $\mathrm{KC}+\mathrm{SF}$ group was significantly reduced compared with that in the $\mathrm{KC}$ group (n=3, Fig. 5M; $\mathrm{P}<0.001$ ). The level of Nox-4 in the $\mathrm{KC}+\mathrm{SF}+\mathrm{ZnPP}$ group was enhanced significantly compared with that in the $\mathrm{KC}+\mathrm{SF}$ group $(\mathrm{n}=3$, Fig. $5 \mathrm{M} ; \mathrm{P}<0.05)$.

SF upregulates the nuclear translocation of Nrf-2 in keratocytes of $\mathrm{KC}$ corneas. Under oxidative stress, Nrf-2 translocates into the cell nucleus and binds with ARE regions of the promoters of genes that encode antioxidant and phase II detoxifying enzymes to weaken cellular oxidative stress (28). Therefore, the present study examined whether the excessive 

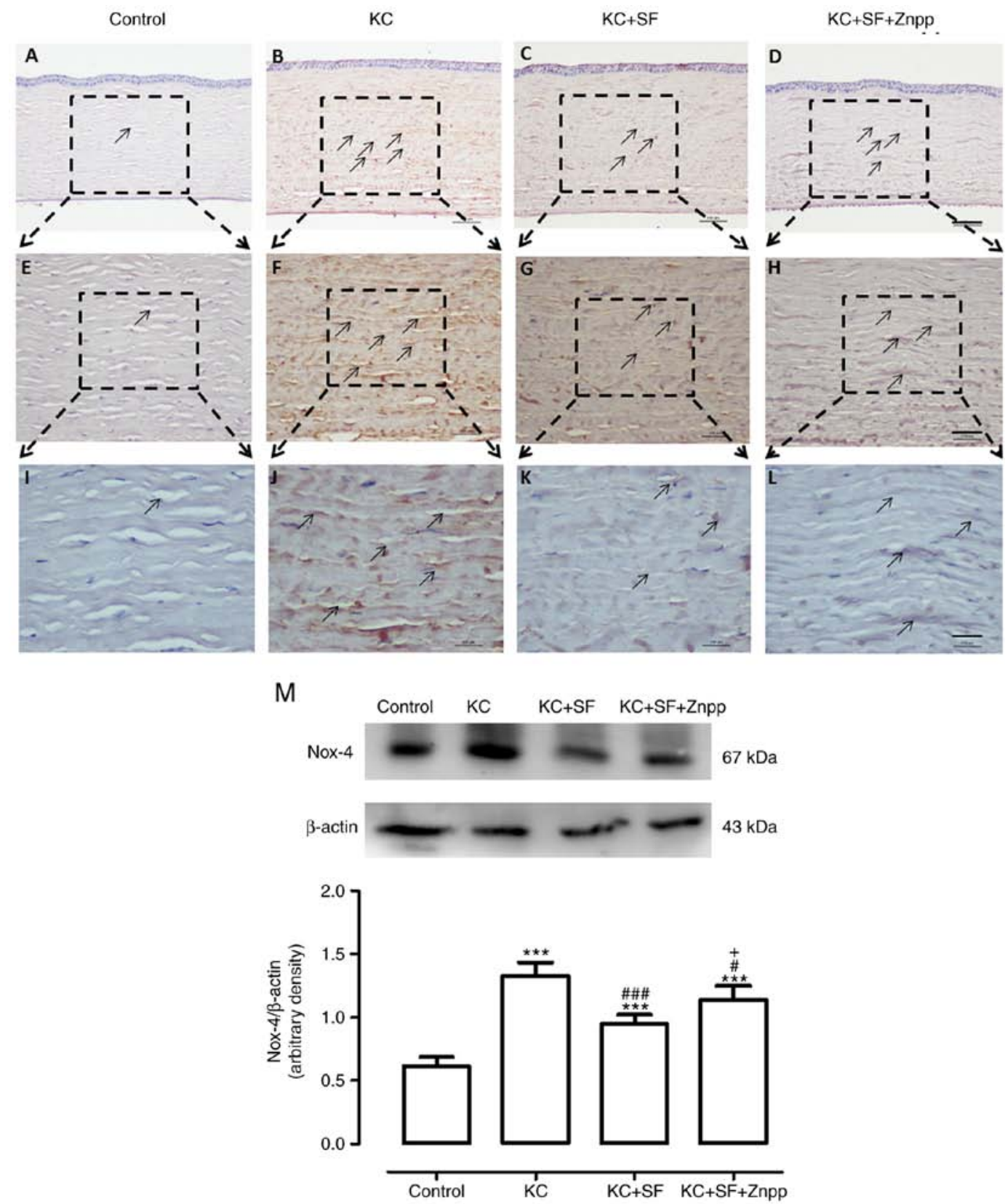

Figure 5. SF downregulates the expression level of Nox-4 in KC corneas. (A-L) Representative micrographs of corneal sections obtained from each group stained with anti-Nox-4 antibody. Black arrows indicate Nox-4-positive cells. (A) Control, (B) KC, (C) KC + SF, and (D) KC + SF + Znpp groups with 10X objective lens (x100 magnification; scale bar=100 $\mu \mathrm{m}$ ). (E) Control, (F) KC, (G) KC $+\mathrm{SF}$, and (H) KC $+\mathrm{SF}+$ Znpp groups with a $20 \mathrm{X}$ objective lens (x200 magnification; scale bar=50 $\mu \mathrm{m}$ ). (I) Control, (J) KC, (K) KC + SF, and (L) KC + SF + Znpp groups with a 40X objective lens (x400 magnification; scale bar $=25 \mu \mathrm{m}) .(\mathrm{M})$ Representative immunoblotting indicating protein levels of Nox-4 in the entire cornea (upper panel) and densitometric analysis of the expression of Nox- 4 relative to the loading control (lower panel). Data are presented as the mean \pm standard deviation; $\mathrm{n}=3$ per group. ${ }^{* * * *} \mathrm{P}<0.001$, vs. Control; ${ }^{*} \mathrm{P}<0.05$

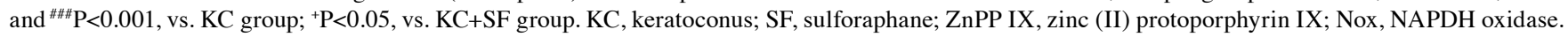

free radicals in $\mathrm{KC}$ corneas were caused by the upregulation of Nrf-2. Images of staining are shown in Fig. 6A-L, The Control group exhibited relatively low Nrf-2 immunoreactivity throughout the cornea (n=4, Fig. 6A, E and I). In the KC group, there was higher Nrf-2 immunoreactivity throughout the entire cornea $(n=4$, Fig. 6B, F and J). The expression of Nrf-2 in the $\mathrm{KC}+\mathrm{SF}$ group was increased more markedly compared with that in the $\mathrm{KC}$ group ( $\mathrm{n}=4$, Fig. $6 \mathrm{C}, \mathrm{G}$ and $\mathrm{K})$. The expression of Nrf-2 in the $\mathrm{KC}+\mathrm{SF}+\mathrm{ZnPP}$ group was lower, compared with that in the $\mathrm{KC}+\mathrm{SF}$ group $(\mathrm{n}=4$, Fig. $6 \mathrm{D}, \mathrm{H}$ and $\mathrm{L})$. Western blot analysis revealed that the basal level of Nrf-2 in the Control cornea was lower than that in the KC cornea. KC induced a significant increase in the expression of Nrf- 2 in the corneas ( $n=3$, Fig. $6 \mathrm{M} ; \mathrm{P}<0.01)$. The level of Nrf- 2 in the KC $+\mathrm{SF}$ group was significantly higher compared with that in the $\mathrm{KC}$ group ( $\mathrm{n}=3$, Fig. $6 \mathrm{M} ; \mathrm{P}<0.001)$. The level of $\mathrm{Nrf}-2$ in the $\mathrm{KC}$ $+\mathrm{SF}+\mathrm{ZnPP}$ group was decreased significantly compared with that in the KC + SF group (n=3, Fig. 6M; P $<0.001)$. SF-induced $\mathrm{Nrf}-2$ pathway activation provided protection against corneal oxidative damage. ZnPP IX, the HO-1 inhibitor, reduced the activity of Nrf-2 on the KC + SF cornea.

SF upregulates the expression of $\mathrm{HO}-1$ in KC corneas. $\mathrm{Nrf}-2$ is a nuclear transcription factor that regulates the expression of 

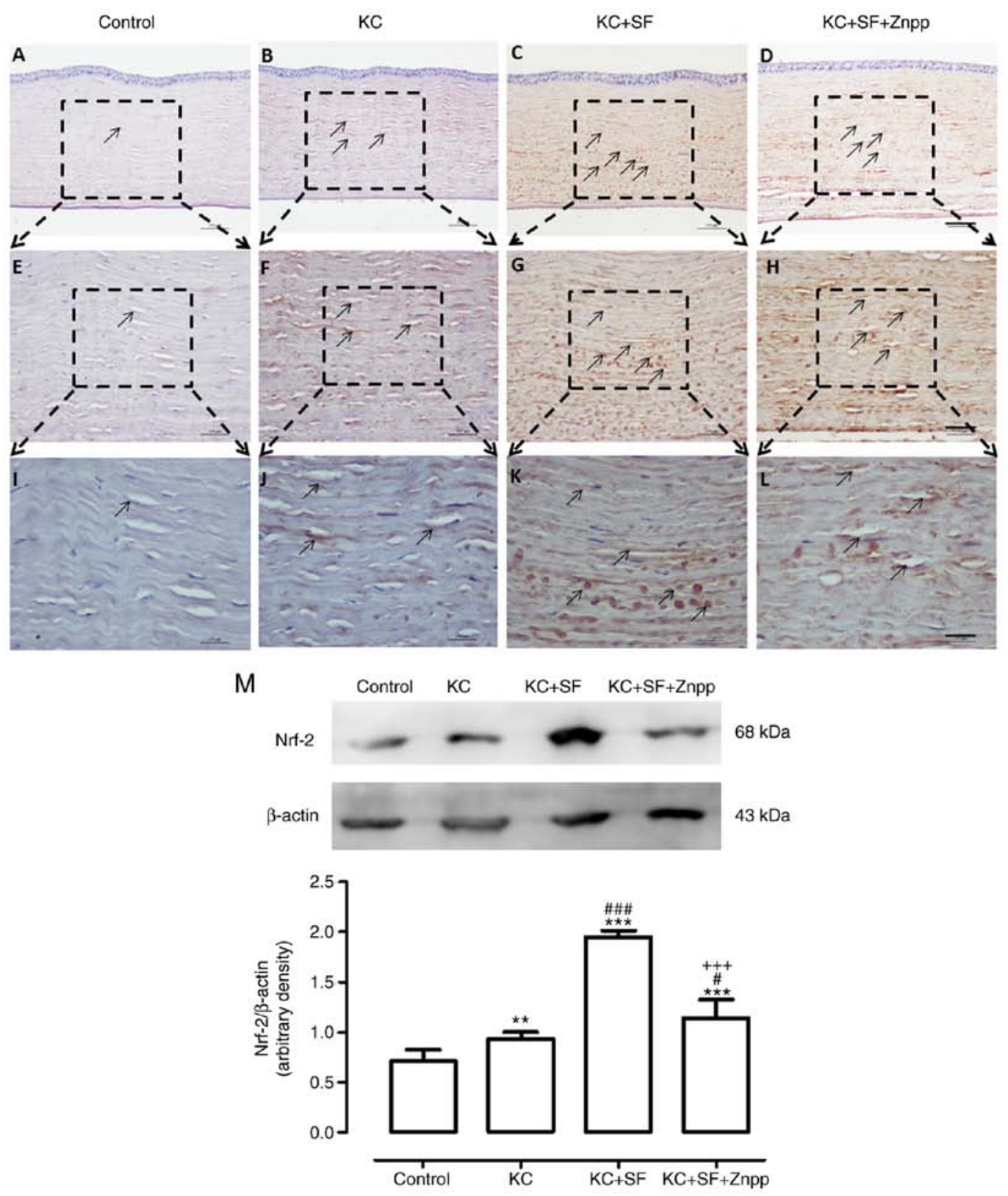

Figure 6. SF upregulates the expression level of Nrf-2 in KC corneas. Representative micrographs of corneal sections obtained from each group stained with anti-Nrf-2 antibody. Black arrows indicate Nrf-2-positive cells. (A) Control, (B) KC, (C) KC + SF, and (D) KC + SF + Znpp groups with a 10X objective lens (x100 magnification, scale bar=100 $\mu \mathrm{m}$ ). (E) Control, (F) KC, (G) KC + SF, and (H) KC + SF + Znpp groups with a $20 \mathrm{X}$ objective lens (x200 magnification; scale bar $=50 \mu \mathrm{m}$ ). (I) Control, (J) KC, (K) KC $+\mathrm{SF}$, and (L) $\mathrm{KC}+\mathrm{SF}+$ Znpp groups with a $40 \mathrm{X}$ objective lens (x400 magnification; scale bar=25 $\mu \mathrm{m}$ ). (M) Representative immunoblotting indicating protein levels of Nrf-2 in the entire cornea (upper panel) and densitometric analysis of the expression of Nrf-2 relative to the loading control (lower panel). Data are presented as the mean \pm standard deviation; $\mathrm{n}=3$ per group. ${ }^{* *} \mathrm{P}<0.01$ and ${ }^{* * * *} \mathrm{P}<0.001$ vs. Control; ${ }^{*} \mathrm{P}<0.05$ and ${ }^{\# \# \# ~} \mathrm{P}<0.001$ vs. KC group; ${ }^{++} \mathrm{P}<0.001$, vs. $\mathrm{KC}+\mathrm{SF}$ group. KC, keratoconus; SF, sulforaphane; ZnPP IX, zinc (II) protoporphyrin IX; Nrf-2, nuclear factor E2-related factor 2.

HO-1 (29). Therefore, the expression of HO-1, a downstream signaling pathway gene of Nrf-2, was investigated by immunohistochemical and western blot analyses in the present study. As shown in the images in Fig. 7A-L, the Control group had weak HO-1 immunoreactivity in the entire cornea $(n=4$, Fig. 7A, E and I). In the $\mathrm{KC}$ group, intense $\mathrm{HO}-1$ immunoreactivity was observed in the entire cornea $(n=4$, Fig. $7 \mathrm{~B}, \mathrm{~F}$ and $\mathrm{J})$. HO-1 immunoreactivity in the $\mathrm{KC}+\mathrm{SF}$ group was increased more markedly compared with that in the $\mathrm{KC}$ group $(\mathrm{n}=4$, Fig. $7 \mathrm{C}$, $\mathrm{G}$ and $\mathrm{K}$ ). HO-1 immunoreactivity in the $\mathrm{KC}+\mathrm{SF}+\mathrm{ZnPP}$ group was decreased compared with that in the $\mathrm{KC}+\mathrm{SF}$ group $(\mathrm{n}=4$, Fig. 7D, H and L). Western blot analysis revealed that the basal expression of HO-1 in the control cornea was lower than that in the $\mathrm{KC}$ cornea. The expression level of HO-1 was significantly enhanced in $\mathrm{KC}$ corneas $(\mathrm{n}=3$, Fig. $7 \mathrm{M} ; \mathrm{P}<0.01)$. The level of HO-1 in the $\mathrm{KC}+\mathrm{SF}$ group was significantly higher compared with that in the $\mathrm{KC}$ group (n=3, Fig. 7M; $\mathrm{P}<0.01)$. The level of $\mathrm{HO}-1$ in the $\mathrm{KC}+\mathrm{SF}+\mathrm{ZnPP}$ group was reduced significantly compared with that in the $\mathrm{KC}+\mathrm{SF}$ group $(\mathrm{n}=3$, Fig. $7 \mathrm{M} ; \mathrm{P}<0.001)$. SF stimulated and induced the protein expression of $\mathrm{HO}-1$ in $\mathrm{KC}$ corneas.

SF decreases the mRNA levels of Nox-2 and Nox-4, and increases the mRNA Nrf-2 and HO-1 in KC corneas. The 

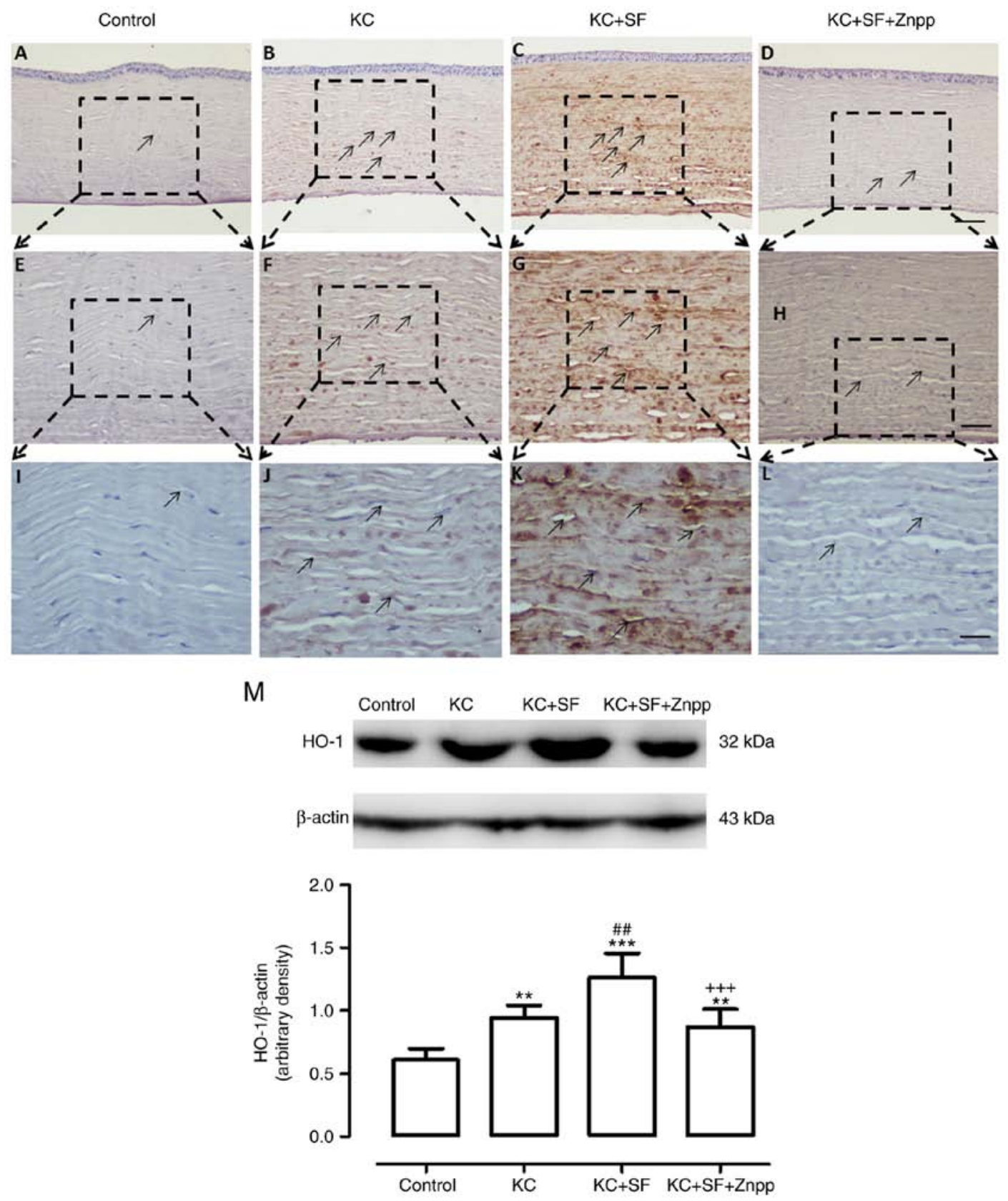

Figure 7. SF upregulates the expression level of HO-1 in KC corneas. Representative micrographs of corneal sections obtained from each group stained with anti-HO-1 antibody. Black arrows indicate HO-1-positive cells. (A) Control, (B) KC, (C) KC + SF, and (D) KC + SF + Znpp groups with a 10X objective lens (x100 magnification; scale bar=100 $\mu \mathrm{m}$; (E) Control, (F) KC, (G) KC + SF, and (H) KC + SF + Znpp groups with a 20X objective lens (x200 magnification); scale bar $=50 \mu \mathrm{m}$ ). (I) Control, (J) KC, (K) KC $+\mathrm{SF}$, and (L) KC $+\mathrm{SF}+$ Znpp groups with a 40X objective lens (x400 magnification; scale bar=25 $\mu \mathrm{m}$. (M) Representative immunoblotting indicating protein levels of HO-1 in the entire cornea (upper panel) and densitometric analysis of the expression of HO-1 relative to the loading control (lower panel). Data are presented as the mean \pm standard deviation; $n=3$ per group. ${ }^{* *} \mathrm{P}<0.01$ and ${ }^{* * *} \mathrm{P}<0.001$, vs. Control; ${ }^{\# \#} \mathrm{P}<0.01$, vs. KC group; ${ }^{++} \mathrm{P}<0.001$, vs. KC+SF group. KC, keratoconus; SF, sulforaphane; ZnPP IX, zinc (II) protoporphyrin IX; HO-1, heme oxygenase-1.

expression levels of relevant antioxidant and oxidation genes, including Nox-2, Nox-4, Nrf-2 and HO-1, were evaluated in corneal stromal cells by RT-qPCR analysis in all experimental groups. As shown in Fig. 8, the RT-qPCR results indicated that, compared with the Control group, the mRNA expression levels of Nox-2, Nox-4, Nrf-2 and HO-1 in the KC group were significantly increased $(n=3$, all $\mathrm{P}<0.05)$, which was consistent with the results of the western blot analysis. The mRNA levels of Nox- 2 and Nox- 4 in the $\mathrm{KC}+\mathrm{SF}$ group were decreased significantly compared with those in the $\mathrm{KC}$ group $(\mathrm{n}=3$, Fig. $8 ; \mathrm{P}<0.01)$. The mRNA levels of $\mathrm{Nrf}-2$ and $\mathrm{HO}-1$ in the $\mathrm{KC}+\mathrm{SF}$ group were increased significantly compared with those in the $\mathrm{KC}$ group $(\mathrm{n}=3$, Fig. $8 ; \mathrm{P}<0.01)$. The mRNA levels of Nox- 2 and Nox -4 in the $\mathrm{KC}+\mathrm{SF}+\mathrm{ZnPP}$ group were increased significantly compared with those in the $\mathrm{KC}+\mathrm{SF}$ group ( $\mathrm{n}=3$ per group, Fig. $8 ; \mathrm{P}<0.05$ ). The mRNA levels of $\mathrm{Nrf}-2$ and $\mathrm{HO}-1$ in the $\mathrm{KC}+\mathrm{SF}+\mathrm{ZnPP}$ group were decreased significantly compared with those in the $\mathrm{KC}+\mathrm{SF}$ group $(\mathrm{n}=3$ per group, Fig. 8; $\mathrm{P}<0.05)$. SF decreased the mRNA levels of Nox-2 and Nox-4, and increased the mRNA levels of Nrf-2 and $\mathrm{HO}-1$ in the $\mathrm{KC}$ corneas. ZnPP IX lessened the protective effect of $\mathrm{SF}$ on the $\mathrm{KC}$ corneas. 


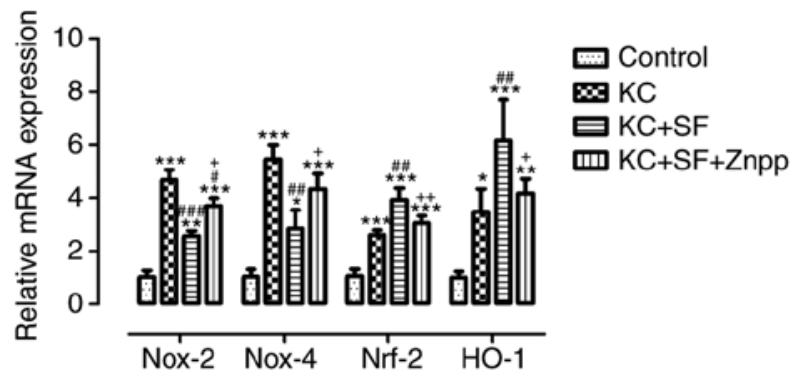

Figure 8. SF decreases the mNRA expression of Nox-2 and Nox-4, and increases the mRNA expression of HO-1 and Nrf-2 in KC corneas. The expression levels of the relevant genes in corneal stromal cells, including HO-1, Nox-2, Nox-4 and Nrf-2, were assessed in the four groups (Control, $\mathrm{KC}, \mathrm{KC}+\mathrm{SF}$, and $\mathrm{KC}+\mathrm{SF}+\mathrm{ZnPP})$. Fold change in gene expression relative to $\beta$-actin was calculated as $2^{-\Delta \Delta \mathrm{Cq}}$. Data are presented as the mean \pm stan dard deviation; $\mathrm{n}=3$ per group. ${ }^{*} \mathrm{P}<0.05,{ }^{* *} \mathrm{P}<0.01$ and ${ }^{* * *} \mathrm{P}<0.001$, vs. Control; ${ }^{\#} \mathrm{P}<0.05,{ }^{\# \#} \mathrm{P}<0.01$ and ${ }^{\# \# \#} \mathrm{P}<0.001$, vs. KC group; ${ }^{+} \mathrm{P}<0.05$ and ${ }^{++} \mathrm{P}<0.01$ vs. KC $+\mathrm{SF}$ group. KC, keratoconus; SF, sulforaphane; ZnPP IX, zinc (II) protoporphyrin IX; Nox, NAPDH oxidase; Nrf-2, nuclear factor E2-related factor 2; HO-1, heme oxygenase-1.

\section{Discussion}

The present study was designed to clarify the possible protective mechanism of SF in a KC rabbit model. SF exerts a protective effect against oxidative stress in numerous biological settings. This protective effect may be induced through the Nrf-2-mediated induction of HO-1. The present study analyzed the expression of an ARE/EpRE-mediated antioxidant protein, $\mathrm{HO}-1$, in the corneas of $\mathrm{KC}$ rabbits and examined the possible effect of Nox on the activation of HO-1. Following surgery, KC caused a significant enhancement of ROS production, leading to a significant increase in $\mathrm{Km}$ and a significant decrease in CCT. These changes caused by KC were weakened or neutralized by SF treatment. Furthermore, SF treatment significantly lowered the protein expression of Nox-2 and Nox-4 and increased the levels of Nrf-2 and HO-1 in the KC cornea. The HO-1 inhibitor, ZnPP IX, reduced the protective effect of SF on the KC cornea. Therefore, the present study may be the first to demonstrate that the protective effect of SF on the KC cornea is, at least be partially, accomplished via the Nrf-2/HO-1 antioxidant pathway.

The corneal KC model mimicked clinical features, including a significant increase in $\mathrm{Km}$ and a significant decrease in CCT compared with the Control group. Previous studies have indicated that corneal ectasia may be generated in vitro and in vivo by treatment with collagenase type II, with increased corneal $\mathrm{Km}$ and decreased CCT $(20,30,31)$. Collagenase type II preferentially degrades collagen I, which is the main collagen component of cornea; therefore, it is possible that exposure to collagenase generates a KC model (32). When considering the natural flattening of the cornea and the reduction in keratometry in both eyes, the total keratometry of the experimental eyes was increased by $>2$ D. Furthermore, the increase in keratometry and decrease in CCT following collagenase exposure lasted for 2 weeks, suggesting that the rabbit model of corneal ectasia generated by collagenase treatment is suitable for use in basic investigations of $\mathrm{KC}$.

In the past two decades, the main focuses of $\mathrm{KC}$ biomechanical investigations have been on alterations in the composition of collagen fibers in the corneal stroma, the connection between fibrin layers, and the role of proteases, however, this has ignored the role of corneal stromal cells. Although corneal stromal cells account for $<5 \%$ of the total corneal matrix, corneal stromal cells are able produce collagen fibers (33-35). Therefore, corneal stromal cells may be the root cause of the role of corneal collagen fibers in KC. Furthermore, corneal stromal cells possess the function of synthesizing glycoproteins and mucins, and may be regulated by various chemical substances $(34,36)$. The present study focused on the role of corneal stromal cells in the pathogenesis of $\mathrm{KC}$, the specific mechanism of oxidative stress in KC stromal cells, and the drug treatment response to this pathogenesis based on the $\mathrm{KC}$ model used.

The overproduction of ROS has been regarded as a pivotal event in $\mathrm{KC}$ corneas in certain studies $(37,38)$, and this was also observed in the present study. Accumulating evidence suggests that oxidative stress is critical in the pathogenesis of $\mathrm{KC}(5,7,38,39)$. This hypothesis was supported by excessive ROS and interference at the transcriptional level and/or antioxidant enzyme activity in $\mathrm{KC}$ corneas compared with controls. However, the application and investigation of antioxidants in the prevention and treatment of $\mathrm{KC}$ have been limited. It has been reported that the antioxidant riboflavin upregulates the expression of antioxidant compounds in $\mathrm{KC}$ stromal cells, downregulates the expression of oxidase genes, and reduces ROS levels in KC (18). Quercetin may be used to reduce oxidative stress regulatory signals involved in the pathogenesis of $\mathrm{KC}(40,41)$. These antioxidative stress drugs may have potential in the clinical prevention and treatment of $\mathrm{KC}$.

$\mathrm{SF}$ is a member of the isothiocyanate family and is obtained from cruciferous vegetables, including Brussels sprouts, cabbage and broccoli (42). As an Nrf-2 activator, SF has been identified to have multiple protective effects, and its role primarily depends on the activation and induction of the phase II expression of antioxidant enzymes $(13,17)$. Numerous studies have reported that SF protects the heart, kidneys, liver and brain from ischemic injury via activation of the Nrf-2/ARE signaling pathway (17,43-45). The protective effects of SF in response to ocular diseases have also been demonstrated. SF has been shown to upregulate primary ARE/EpRE-mediated antioxidants and alleviate oxidative stress-induced corneal endothelial cell apoptosis in Fuchs endothelial corneal dystrophy through enhancing the nuclear translocation of Nrf-2 (46). SF treatment has also been reported to protect retinal pigment epithelial and photoreceptor cells from optical damage and postpone retinal photoreceptor cell degeneration in mice through upregulating Nrf-2 $(47,48)$. However, to the best of our knowledge, there has been no report on the effect of SF on corneal stromal cells in KC and its clinical features. In the present study, it was demonstrated that SF significantly inhibited ROS generation in KC stromal cells, enhanced corneal $\mathrm{Km}$ and reduced $\mathrm{CCT}$ in $\mathrm{KC}$, suggesting that $\mathrm{SF}$ exhibits an antioxidant function in $\mathrm{KC}$ corneas and delays the progress of $\mathrm{KC}$ disease. This is the first evidence, to the best of our knowledge, of the antioxidative effect of SF on corneal stromal cells in a $\mathrm{KC}$ model.

The mechanism underlying the effect of SF in reducing oxidative stress response in $\mathrm{KC}$ was evaluated further 
by analyzing the expression of genes associated with the Nrf-2/ARE signaling pathway. Unlike other oxidoreductases, the Nox family is considered to be a distinct enzymatic source of cellular ROS generation as these enzymes are among the most effective ROS producers (49). Cornea stromal cells have been demonstrated to be capable of producing $\operatorname{ROS}(8,27)$. In the present study, KC induced the generation of ROS, Nox-2 and Nox-4 in corneal stromal cells. The production of ROS in KC corneas may be through the activation of Nox-2 and Nox-4. In the present study, it was demonstrated that SF significantly downregulated the expression levels of Nox-2 and Nox-4 in the $\mathrm{KC}$ corneas. It was suggested that the downregulation in the expression of Nox-2 and Nox-4 following treatment with SF may act as an underlying contributor to the Nrf-2/ARE signaling pathway and regulated gene expression, and may be involved in the antioxidative stress protective mechanism in $\mathrm{KC}$ corneas. This may provide valuable information on the mechanisms involved in the pathogenesis of $\mathrm{KC}$. The results suggested that SF has an anti-Nox-dependent ROS generating role in the $\mathrm{KC}$ cornea, possibly by inactivating the expression of Nox-2 and Nox-4.

The downregulation of Nox-2 and Nox- 4 following $\mathrm{SF}$ treatment may promote activation of the Nrf-2/ARE signaling pathway and regulate the expression of associated genes, and may be involved in the protective mechanism of $\mathrm{SF}$ on oxidative stress in $\mathrm{KC}$. Nrf-2 is critical to maintain the level of intracellular glutathione and redox balance, and it is also important in resisting oxidative stress via activating the expression of several ROS-detoxifying enzymes and stimulating the production of antioxidants (50). Under normal physiological conditions, Nrf-2 is sequestered in the cell cytosol via an interaction with Keap1. Under oxidative stress conditions, Nrf-2 dissociates from Keap1, accumulates in the nucleus, and then binds to ARE regions in the promoters of antioxidants, including Nrf-2 itself and HO-1 combined with small Maf proteins $(51,52)$. Several types of cellular stressors induce the protein expression of HO-1 through redox-sensitive factors, including Nrf-2, which has been identified as a pivotal transcription factor controlling antioxidant gene expression $(53,54)$. HO-1 catalyzes the rate-limiting process of heme oxidative degradation to biliverdin, releasing carbon monoxide and iron. HO-1 is important in sustaining oxidative/antioxidant equilibrium (55). In the present study, it was observed that SF treatment increased the accumulation of nuclear Nrf-2 and upregulated $\mathrm{HO}-1$ in the corneas of the $\mathrm{KC}$ rabbit model. The HO-1 inhibitor, ZnPP IX, reduced the activity of Nrf-2 in the $\mathrm{KC}+\mathrm{SF}$ cornea. The upregulation of Nrf-2 by SF treatment was associated with an increased level of $\mathrm{HO}-1$ in the $\mathrm{KC}$ corneas. The induction of HO-1 and Nrf-2 by SF may decrease damage in corneal stromal cells via recovering the balance of antioxidants and pro-oxidants in the cornea. This suggested that the activation of HO-1 and Nrf-2 may represent a key signaling pathway for mitigating the degree of cell damage attributed to oxidative stress in $\mathrm{KC}$ corneas.

The findings of the present study suggested that the activation of Nrf-2, and the protective effect of SF, were likely to be due to control of the oxidative stress response via the induction of HO-1. SF induced a significant decrease of ROS production and increase of HO-1 protein in the present study. The ability of SF-mediated free radical production and its reaction with cysteine residues of Keap1 (56) lead to Nrf-2 defense signaling pathway activation. ZnPP IX, an HO-1 inhibitor, attenuated the protective effects of SF against oxidative stress injury in the KC cornea. These observations suggested that the Nrf-2/HO-1 antioxidant signaling pathway was associated with the protective effect of SF on KC-induced injury in the rabbit cornea. SF may reduce the damage from oxidative stress to corneal stromal cells by activating the Nrf-2/HO-1 axis, thereby reducing the corneal $\mathrm{Km}$ and increasing $\mathrm{CCT}$, and delaying the progression of $\mathrm{KC}$. SF may provide a novel and important theoretical basis for $\mathrm{KC}$ drug treatment; it may function as an underlying prophylactic drug resisting oxidative stress in corneal $\mathrm{KC}$ injury.

$\mathrm{N}$-acetylcysteine (NAC) is a compound containing active sulfhydryl groups, which enhances antioxidation and anti-free radical damage by direct antioxidation effects (57). NAC, an antioxidant and ROS scavenger, is able to inhibit or prevent damage and cell death in corneas (58). The majority of reports consider NAC to be a direct, fast-acting, short-acting antioxidant. In addition, various ophthalmic formulations of NAC have been widely utilized for other corneal disorders $(59,60)$. Compared with NAC, SF is a notable indirect antioxidant. It functions by stimulating the free radical scavenging system of the body and promoting the body to produce increased free radical scavenging enzymes. SF, a long-lasting antioxidant, has a long half-life and is not consumed in the antioxidation process. Therefore, the antioxidant response of SF was examined in the present study, with a focus on the protective effect of SF on $\mathrm{KC}$, including reducing the curvature of the $\mathrm{KC}$ and increasing the thickness of the $\mathrm{KC}$. The specific mechanisms of this protective effect were examined. However, further investigations can be performed to detect the protective effect of NAC on KC corneas, or combined NAC and SF drugs, and provide further ideas for the treatment of $\mathrm{KC}$.

Previous studies have indicated that the pathogenesis of $\mathrm{KC}$ consists of corneal thinning together with a reduced number of keratocytes, attributed to excessive oxidative stress and increased catalase activity (61). No significant reduction in the number of corneal stromal cells was observed in the present study. This may be due to the fact that the level of ROS production was not high enough, the duration was short, and the endogenous compensatory mechanism was involved, thus reducing damage to corneal stromal cells by oxidative stress in the KC model. The antioxidant SF may have a discernible beneficial effect on the inferred pathogenesis of $\mathrm{KC}$ by moderating the presence of ROS. These results support the potential effectiveness of antioxidants as a potential therapy, which is directed at the pathogenesis of the disease by promoting normal synthesis and reducing ROS levels. However, further investigations are warranted to solve important problems, including the assessment of HO-1 activities in various settings by measuring bilirubin spectrophotometrically, changes in the Nrf-2/HO-1 signaling pathway in the cell culture of $\mathrm{KC}$ stroma cells, increasing the time window of targeting oxidative stress with SF, and assessing the functional state of rescued corneal stroma cells.

In conclusion, $\mathrm{KC}$ induced an increase in ROS generation, and caused a marked increase in $\mathrm{Km}$ and a marked decrease in CCT. These effects were neutralized or reversed by SF treatment. Treatment with SF significantly decreased 
the expression levels of Nox-2 and Nox-4 and increased the expression levels of $\mathrm{Nrf}-2$ and $\mathrm{HO}-1$ in the $\mathrm{KC}$ corneas. It was found that oxidative stress was present in the rabbit $\mathrm{KC}$ model, and ROS production primarily originated from Nox-2 and Nox-4 in the KC corneas. SF activated the Nrf-2/HO-1 pathway as a target to resist the oxidative stress response of $\mathrm{KC}$, thereby reducing corneal $\mathrm{Km}$, increasing corneal $\mathrm{CCT}$, and preventing the progression of $\mathrm{KC}$. These results suggested that SF may be an appropriate drug for the treatment of $\mathrm{KC}$. Overall, these experimental results suggested that the protective effect of SF on $\mathrm{KC}$ corneas was mediated at least in part by activating the Nrf-2/HO-1 antioxidant pathway. These novel findings may improve current understanding of $\mathrm{KC}$ disease signaling pathways and thus reinforce the clinical treatment and management of $\mathrm{KC}$.

\section{Acknowledgements}

Not applicable.

\section{Funding}

This study was supported by funding from the National Natural Science Foundation of China (grant no. 11372011).

\section{Availability of data and materials}

All data generated or analyzed during this study are included in this article.

\section{Authors' contributions}

All authors conceived and designed the experiments. RL performed the experiments and analyzed the data. RL wrote the manuscript. XY modified the manuscript. Both authors read and approved the final manuscript.

\section{Ethics approval and consent to participate}

All procedures performed in studies involving animals were approved by the Ethical Committee of Peking University First Hospital. All animals used in the present study were treated in accordance with the Association for Research in Vision and Ophthalmology Statement for the Use of Animals in Ophthalmic and Vision Research.

\section{Patient consent for publication}

Not applicable.

\section{Competing interests}

The authors declare that they have no competing interests.

\section{References}

1. Rabinowitz YS: Keratoconus. Surv Ophthalmol 42: 297-319, 1998

2. Katsoulos C, Karageorgiadis L, Vasileiou N, Mousafeiropoulos T and Asimellis G: Customized hydrogel contact lenses for keratoconus incorporating correction for vertical coma aberration. Ophthalmic Physiol Opt 29: 321-329, 2009.
3. Abu-Amero KK, Al-Muammar AM and Kondkar AA: Genetics of keratoconus: Where do we stand? J Ophthalmol 2014: 641708, 2014.

4. Nielsen K, Hjortdal J, Pihlmann M and Corydon TJ: Update on the keratoconus genetics. Acta Ophthalmol 91: 106-113, 2013.

5. Kenney MC, Chwa M, Atilano SR, Tran A, Carballo M, Saghizadeh M, Vasiliou V, Adachi W and Brown DJ: Increased levels of catalase and cathepsin V/12 but decreased TIMP-1 in keratoconus corneas: Evidence that oxidative stress plays a role in this disorder. Investig Ophthalmol Vis Sci 46: 823-832, 2005.

6. Chwa M, Atilano SR, Hertzog D, Zheng H, Langberg J, Kim DW and Kenney MC: Hypersensitive response to oxidative stress in keratoconus corneal fibroblasts. Investig Ophthalmol Vis Sci 49: 4361-4369, 2008

7. Buddi R, Lin B, Atilano SR, Zorapapel NC, Kenney MC and Brown DJ: Evidence of oxidative stress in human corneal diseases. J Histochem Cytochem 50: 341-351, 2002.

8. Chwa M, Atilano SR, Reddy V, Jordan N, Kim DW and Kenney MC: Increased stress-induced generation of reactive oxygen species and apoptosis in human keratoconus fibroblasts. Investig Ophthalmol Vis Sci 47: 1902-1910, 2006.

9. Jeong WS, Jun M and Kong AN: Nrf2: A potential molecular target for cancer chemoprevention by natural compounds. Antioxid Redox Signal 8: 99-106, 2006.

10. Siow RC, Ishii T and Mann GE: Modulation of antioxidant gene expression by 4-hydroxynonenal: Atheroprotective role of the Nrf2/ARE transcription pathway. Redox Rep 12: 11-15, 2007.

11. Itoh K, Chiba T, Takahashi S, Ishii T, Igarashi K, Katoh Y, Oyake T, Hayashi N, Satoh K, Hatayama I, et al: An Nrf2/small maf heterodimer mediates the induction of phase II detoxifying enzyme genes through antioxidant response elements. Biochem Biophys Res Commun 236: 313-322, 1997.

12. Cheng X, Siow RCM and Mann GE: Impaired redox signaling and antioxidant gene expression in endothelial cells in diabetes: A role for mitochondria and the nuclear factor-E2-related factor 2-Kelch-like ECH-associated protein 1 defense pathway. Antioxid Redox Signal 14: 469-487, 2011.

13. Zhang Y, Talalay P, Cho CG and Posner GH: A major inducer of anticarcinogenic protective enzymes from broccoli: Isolation and elucidation of structure. Proc Natl Acad Sci USA 89: 2399-2403, 1992.

14. Zhao J, Kobori N, Aronowski J and Dash PK: Sulforaphane reduces infarct volume following focal cerebral ischemia in rodents. Neurosci Lett 393: 108-112, 2006.

15. Danilov CA, Chandrasekaran K, Racz J, Soane L, Zielke C and Fiskum G: Sulforaphane protects astrocytes against oxidative stress and delayed death caused by oxygen and glucose deprivation. Glia 57: 645-656, 2009.

16. Tarozzi A, Morroni F, Merlicco A, Hrelia S, Angeloni C, Cantelli-Forti G and Hrelia P: Sulforaphane as an inducer of glutathione prevents oxidative stress-induced cell death in a dopaminergic-like neuroblastoma cell line. J Neurochem 111: 1161-1171, 2009.

17. Piao CS, Gao S, Lee GH, Kim DS, Park BH, Chae SW, Chae HJ and Kim SH: Sulforaphane protects ischemic injury of hearts through antioxidant pathway and mitochondrial K(ATP) channels. Pharmacol Res 61: 342-348, 2010.

18. Cheung IMY, Mcghee $\mathrm{CN}$ and Sherwin T: Beneficial effect of the antioxidant riboflavin on gene expression of extracellular matrix elements, antioxidants and oxidases in keratoconic stromal cells. Clin Exp Optom 97: 349-355, 2014.

19. Clark JE, Foresti R, Green CJ and Motterlini R: Dynamics of haem oxygenase-1 expression and bilirubin production in cellular protection against oxidative stress. Biochem J $348 \mathrm{Pt}$ 3: 615-619, 2000.

20. Qiao J, Li H, Tang Y, Song W, Rong B, Yang S, Wu Y and Yan X: A rabbit model of corneal Ectasia generated by treatment with collagenase type II. BMC Ophthalmol 18: 94, 2018.

21. Zheng H, Whitman SA, Wu W, Wondrak GT, Wong PK, Fang D and Zhang DD: Therapeutic potential of Nrf2 activators in streptozotocin-induced diabetic nephropathy. Diabetes 60: 3055-3066, 2011.

22. Park J, Kang JW and Lee SM: Activation of the cholinergic anti-inflammatory pathway by nicotine attenuates hepatic ischemia/reperfusion injury via heme oxygenase-1 induction. Eur J Pharmacol 707: 61-70, 2013.

23. Wang W, Wang F, Shi L, Jia X and Lin L: Role of heme oxygenase-1/carbon monoxide system in pulmonary ischemia-reperfusion injury. Interact Cardiovasc Thorac Surg 9: 159-162, 2009 
24. He M, Pan $\mathrm{H}$, Xiao $\mathrm{C}$ and $\mathrm{Pu} \mathrm{M}$ : Roles for redox signaling by NADPH oxidase in hyperglycemia-induced heme oxygenase-1 expression in the diabetic retina. Investig Opthalmology Vis Sci 54: 4092-4101, 2013.

25. Fleige S, Walf V, Huch S, Prgomet C, Sehm J and Pfaffl MW: Comparison of relative mRNA quantification models and the impact of RNA integrity in quantitative real-time RT-PCR. Biotechnol Lett 28: 1601-1613, 2006.

26. Livak KJ and Schmittgen TD: Analysis of relative gene expression data using real-time quantitative PCR and the 2(-Delta Delta C(T)) method. Methods 25: 402-408, 2001.

27. O'Brien WJ, Heimann T and Rizvi F: NADPH oxidase expression and production of superoxide by human corneal stromal cells. Mol Vis 15: 2535-2543, 2009.

28. Kermer P, Ankerhold R, Klöcker N, Krajewski S, Reed JC and Bähr M: Caspase-9: Involvement in secondary death of axotomized rat retinal ganglion cells in vivo. Brain Res Mol Brain Res 85: 144-150, 2000 .

29. Itoh K, Wakabayashi N, Katoh Y, Ishii T, Igarashi K, Engel JD and Yamamoto M: Keapl represses nuclear activation of antioxidant responsive elements by Nrf2 through binding to the amino-terminal Neh2 domain. Genes Dev 13: 76-86, 1999.

30. Hong CW, Sinha-Roy A, Schoenfield L, Mcmahon JT and Dupps WJ Jr: Collagenase-mediated tissue modeling of corneal ectasia and collagen cross-linking treatments. Investig Ophthalmol Vis Sci 53: 2321-2327, 2012.

31. Wang X, Huang Y, Jastaneiah S, Majumdar S, Kang JU, Yiu SC, Stark W and Elisseeff JH: Protective effects of soluble collagen during ultraviolet-A crosslinking on enzyme-mediated corneal ectatic models. PLoS One 10: e0136999, 2015.

32. Egeblad M and Werb Z: New functions for the matrix metalloproteinases in cancer progression. Nat Rev Cancer 2: 161-174, 2002.

33. Davidson AE, Hayes S, Hardcastle AJ and Tuft SJ: The pathogenesis of keratoconus. Eye (Lond) 28: 189-195, 2014.

34. Meek KM and Knupp C: Corneal structure and transparency. Prog Retin Eye Res 49: 1-16, 2015.

35. Elsheikh A, Ross S, Alhasso D and Rama P: Numerical study of the effect of corneal layered structure on ocular biomechanics. Curr Eye Res 34: 26-35, 2009.

36. Jester JV, Moller-Pedersen T, Huang J, Sax CM, Kays WT, Cavangh HD, Petroll WM and Piatigorsky J: The cellular basis of corneal transparency: Evidence for 'corneal crystallins'. J Cell Sci 112: 613-622, 1999 .

37. Karamichos D, Hutcheon a EK, Rich CB, Trinkaus-Randall V, Asara JM and Zieske JD: In vitro model suggests oxidative stress involved in keratoconus disease. Sci Rep 4: 4608, 2014.

38. Arnal E, Peris-Martínez C, Menezo JL, Johnsen-Soriano S and Romero FJ: Oxidative stress in keratoconus? Invest Ophthalmol Vis Sci 52: 8592-8597, 2011.

39. Gondhowiardjo TD and van Haeringen NJ: Corneal aldehyde dehydrogenase, glutathione reductase, and glutathione S-transferase in pathologic corneas. Cornea 12: 310-314, 1993.

40. McKay TB, Sarker-Nag A, Lyon D, Asara JM and Karamichos D: Quercetin modulates keratoconus metabolism in vitro. Cell Biochem Funct 33: 341-350, 2015.

41. McKay TB, Lyon D, Sarker-Nag A, Priyadarsini S, Asara JM and Karamichos D: Quercetin attenuates lactate production and extracellular matrix secretion in keratoconus. Sci Rep 5: 9003, 2015.

42. Fahey JW, Holtzclaw WD, Wehage SL, Wade KL, Stephenson KK and Talalay P: Sulforaphane bioavailability from glucoraphanin-rich broccoli: Control by active endogenous myrosinase. PLoS One 10: e0140963, 2015.

43. Zhao HD, Zhang F, Shen G, Li YB, Li YH, Jing HR, Ma LF, Yao JH and Tian XF: Sulforaphane protects liver injury induced by intestinal ischemia reperfusion through Nrf2-ARE pathway. World J Gastroenterol 16: 3002-3010, 2010.

44. Ping Z, Liu W, Kang Z, Cai J, Wang Q, Cheng N, Wang S, Wang S, Zhang JH and Sun X: Sulforaphane protects brains against hypoxic-ischemic injury through induction of Nrf2-dependent phase 2 enzyme. Brain Res 1343: 178-185, 2010.
45. Yoon HY, Kang NI, Lee HK, Jang KY, Park JW and Park BH: Sulforaphane protects kidneys against ischemia-reperfusion injury through induction of the Nrf2-dependent phase 2 enzyme. Biochem Pharmacol 75: 2214-2223, 2008.

46. Ziaei A, Schmedt T, Chen Y and Jurkunas UV: Sulforaphane decreases endothelial cell apoptosis in Fuchs endothelial corneal dystrophy: A novel treatment. Investig Ophthalmol Vis Sci 54: 6724-6734, 2013

47. Tanito M, Masutani H, Kim YC, Nishikawa M, Ohira A and Yodoi J: Sulforaphane induces thioredoxin through the antioxidant-responsive element and attenuates retinal light damage in mice. Investig Ophthalmol Vis Sci 46: 979-987, 2005.

48. Kong L, Tanito M, Huang Z, Li F, Zhou X, Zaharia A, Yodoi J, McGinnis JF and Cao W: Delay of photoreceptor degeneration in tubby mouse by sulforaphane. J Neurochem 101: 1041-1052, 2007.

49. Lambeth JD: NOX enzymes and the biology of reactive oxygen. Nat Rev Immunol 4: 181-189, 2004.

50. Kensler TW, Wakabayashi $\mathrm{N}$ and Biswal S: Cell survival responses to environmental stresses via the Keap1-Nrf2-ARE pathway. Annu Rev Pharmacol Toxicol 47: 89-116, 2007.

51. Kobayashi $M$ and Yamamoto M: Molecular mechanisms activating the Nrf2-Keap1 pathway of antioxidant gene regulation. Antioxid Redox Signal 7: 385-394, 2005.

52. Kang KW, Lee SJ and Kim SG: Molecular mechanism of nrf2 activation by oxidative stress. Antioxid Redox Signal 7: 1664-1673, 2005.

53. Ishii T, Itoh K, Ruiz E, Leake DS, Unoki H, Yamamoto $M$ and Mann GE: Role of Nrf2 in the regulation of CD36 and stress protein expression in murine macrophages: Activation by oxidatively modified LDL and 4-hydroxynonenal. Circ Res 94: 609-616, 2004

54. Wakabayashi N, Slocum SL, Skoko JJ, Shin S and Kensler TW: When NRF2 talks, who's listening? Antioxid Redox Signal 13: 1649-1663, 2010

55. Ryter SW, Alam J and Choi AMK: Heme oxygenase-1/carbon monoxide : From basic science to therapeutic applications. Physiol Rev 86: 583-650, 2006.

56. Hu C, Eggler AL, Mesecar AD and Van Breemen RB: Modification of Keapl cysteine residues by sulforaphane. Chem Res Toxicol 24: 515-521, 2011.

57. Kizilgun M, Poyrazoglu Y, Oztas Y, Yaman H, Cakir E, Cayci T, Akgul OE, Kurt YG, Yaren H, Kunak ZI, et al: Beneficial effects of N-acetylcysteine and ebselen on renal ischemia/reperfusion injury. Ren Fail 33: 512-517, 2011.

58. Rosani U, Tarricone E, Venier P, Brun P, Deligianni V, Zuin M, Martines E, Leonardi A and Brun P: Atmospheric-pressure cold plasma induces transcriptional changes in ex vivo human corneas. PLoS One 10: e0133173, 2015.

59. Yalçin E, Altin F, Cinhüseyinoglue F and Arslan MO: $\mathrm{N}$-acetylcysteine in chronic blepharitis. Cornea 21: 164-168, 2002.

60. Schmidl D, Werkmeister R, Kaya S, Unterhuber A, Witkowska KJ Baumgartner R, Höller S, O'Rourke M, Peterson W, Wolter A, et al: A controlled, randomized double-blind study to evaluate the safety and efficacy of chitosan-N-acetylcysteine for the treatment of dry eye syndrome. J Ocul Pharmacol Ther 33: 375-382, 2017.

61. Ishii T, Miyazawa M, Onouchi H, Yasuda K, Hartman PS and Ishii N: Model animals for the study of oxidative stress from complex II. Biochim Biophys Acta 1827: 588-597, 2013.

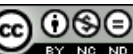

This work is licensed under a Creative Commons Attribution-NonCommercial-NoDerivatives 4.0 International (CC BY-NC-ND 4.0) License. 